\title{
OFERTA DE PROTEÍNA E SÓDIO DOS PRATOS PROTEICOS EM REFEIÇÕES DE UMA UNIDADE DE ALIMENTAÇÃO
}

\author{
SUPPLY OF PROTEIN AND SODIUM FROM CHOSEN PROTEIN DISHES IN A FOOD \\ SERVICE
}

\section{Stela dos Reis Villa ${ }^{1}$ \\ Vanessa Melo ${ }^{2}$ \\ Mônica Glória Neumann Spinelli ${ }^{3}$}

Resumo: Objetivo avaliar a oferta de proteína e sódio dos pratos proteicos escolhidos na refeição, almoço, em uma Unidade de Alimentação e Nutrição (UAN). Metodologia: Foi realizado um estudo observacional descritivo com comensais, em um restaurante de uma UAN, do município de São Paulo - SP. A refeição, almoço, dessa unidade oferece, diariamente, dois pratos proteicos. O cálculo do número de porções dos dois pratos e de sua quantidade em gramas foi obtido pela média das escolhas dos pratos. Foram calculados a quantidade de proteínas, seu valor calórico e a quantidade de sódio, proporcionados pelos pratos proteicos escolhidos. Os resultados foram comparados com os valores recomendados pelo Programa de Alimentação do Trabalhador (PAT). Resultados: Os clientes se serviram, em média, com 1,12 porção do alimento preparado na UAN; e com 1,51 de processados. A porção média escolhida do prato proteico foi de 295,53 g, variando entre 146,00 e 462,70 g. A quantidade, em gramas, de proteína variou entre 37,51 g e 111,23 g e a de sódio entre 803,68 mg e 2188,10 mg. Conclusão: Nos dias analisados na UAN, o porcionamento dos pratos proteicos excedeu às recomendações, e a quantidade média de proteínas e de sódio das escolhas proteicas na refeição almoço ultrapassa o valor máximo recomendado pelo PAT, indicando que a livre demanda pode ser fator de risco para escolhas saudáveis.

Palavras-chave: Proteína; sódio; almoço; restaurante; trabalhadores; comportamento alimentar.

Abstract: Objective: To evaluate the supply of protein and sodium from protein dishes chosen at lunch time in a food service. Methodology: a descriptive observational study was carried out with diners at a restaurant of a food service in São Paulo-SP. The lunch meal from this unit offers daily two protein dishes and their quantity in grams was obtained by averaging the choices of dishes. The amount of protein, its caloric value and the amount of sodium provided by the dishes were calculated. The results were compared with the values recommended by the worker's food program. Results: Natural dish average was 1.12 portions and processed food was 1.51. The average portion chosen of the protein dish was $295.53 \mathrm{~g}$, ranging from 146.00 to $462.70 \mathrm{~g}$. The protein quantity in grams ranged between $37.51 \mathrm{~g}$ and $111.23 \mathrm{~g}$ and the sodium amount, between $803.68 \mathrm{mg}$ and $2188.10 \mathrm{mg}$. Conclusion: During the days of analysis, the portioning of the protein dishes exceeded the recommendations. The average amount of protein and sodium from the lunch meal choices exceeds the maximum value recommended by the worker's food program, indicating that the free demand can be a risk factor for healthy choices.

Keywords: Protein; sodium; lunch; restaurant; workers; feeding behavior.

\section{INTRODUÇÃO}

\footnotetext{
${ }^{1}$ Nutricionista graduada pela Universidade Paulista - UNIP, Brasil. E-mail: strelavilla@hotmail.com.

2 Nutricionista graduada pela Universidade Paulista - UNIP, Brasil. E-mail: melo.vanessa@hotmail.com.

3 Docente do Curso de Nutrição da Universidade Paulista e Professora Adjunta da Universidade Presbiteriana Mackenzie, Brasil. E-mail: monicaspi404@gmail.com.
} 
O Programa de Alimentação do Trabalhador (PAT) foi instituído com o propósito de melhorar a qualidade de vida do trabalhador (BRASIL, 2006). Na prática, porém, estudos têm demonstrado que a alimentação fornecida pelo programa apresenta, na maior parte das vezes, uma inadequação na proporção dos nutrientes, com um excesso de proteínas e sódio (SAVIO et al, 2005; SALAS et al, 2009; SPINELLI; KAWASHIMA; EGASHIRA, 2011; BARBOSA; BARROS; SPINELLI, 2012; BRITO; SPINELLI, 2016).

Essa inadequação agravou-se nos últimos anos a partir da instituição do sistema self-service, que permite ao trabalhador a escolha dos alimentos por livre demanda, ou seja, o próprio comensal exerce sua auto determinação. Essa modalidade de serviço não é sinônimo de alimentação adequada e/ou saudável, pois, de acordo com Abreu, Spinelli e Pinto (2016) e Whitworth (2003), nem sempre existe o controle das quantidades servidas, aliado ao fato da supervalorização da carne e do excesso de sódio na alimentação do brasileiro (IBGE, 2011; CARVALHO et al, 2013; RIBEIRO; CORÇÃO, 2013).

Segundo o PAT (BRASIL, 2006), a grande refeição (almoço, jantar ou ceia) deve apresentar entre 600 a 800 calorias. Desse total energético, 60 a 120 calorias devem provir das proteínas (10\% a 15\% das calorias da refeição); ou seja, entre 15 a $30 \mathrm{~g}$ do nutriente e entre 720 e $960 \mathrm{mg}$ de sódio (30 a 40\% das necessidades diárias).

Nesse contexto, este trabalho teve como objetivo avaliar a oferta de proteína e sódio fornecidos pelos alimentos proteicos servidos como prato principal, em livre demanda, em uma Unidade de Alimentação e Nutrição (UAN), no município de São Paulo - SP.

\section{METODOLOGIA}

Foi realizado um estudo observacional descritivo em um restaurante de uma Unidade de Alimentação e Nutrição (UAN), do município de São Paulo, que fornece em média, 450 refeições/dia. O sistema de distribuição, na UAN, é centralizado, as refeições são produzidas e distribuídas no mesmo local, por meio do serviço self service (de livre demanda). São oferecidos, diariamente, como prato principal, dois pratos proteicos e duas opções, que foram excluídas do estudo, devido à pouca quantidade consumida pelos clientes.

São oferecidos tanto pratos proteicos preparados na própria na UAN quanto pratos proteicos processados industrialmente. Foi definido como prato proteico preparado na UAN a preparação elaborada a partir de carne crua temperada antes do processo de cocção e preparações processadas industrialmente, aquelas que já vêm temperadas e semi-prontas para passarem por processo de aquecimento ou cocção. Para a quantificação da porção e dos nutrientes da preparação proteica preparada na 
própria UAN, foram coletados dados sobre a quantidade de carne preparada em quilos, tipo de pré-preparo e preparo, gramas por porção do alimento já pronto e o sal acrescentado no preparo. Nas porções dos pratos proteicos processados industrialmente, a quantificação foi realizada por meio das informações dos dados coletados a partir dos rótulos das embalagens (quantidade de proteínas em gramas e sódio em miligramas).

Os dados referentes às quantidades dos pratos proteicos, escolhidos na hora da distribuição da refeição, foram coletados por observação, sem que os clientes da unidade se dessem conta, para não haver interferência no número de porções servidas. A observação foi realizada durante o almoço, que é servido de segunda a sexta feira, por 11 dias não consecutivos. À medida que o cliente se servia, eram registrados, na planilha, o número de porções de cada um dos pratos escolhidos. Como o processo requeria atenção, do número total de almoços do dia, foram registradas, em média, a escolha de 164 clientes/dia, ou seja, foi registrado 1 cliente a cada 2 ou 3 que se serviam na fila.

Os dados foram compilados em planilha elaborada pelas pesquisadoras contendo as variáveis: data da coleta, número de clientes, tipo e quantidade em porções de cada preparação proteica (no caso, prato proteico 1 e 2).

O preenchimento da planilha com as anotações sobre a quantidade de porções se deu durante a distribuição, em frente às pistas quentes.

Os dados foram transpostos para planilhas do programa Microsoft Excel 2010, os resultados analisados e as médias calculadas com respectivos desvios padrão.

Para a quantificação de uma porção em gramas dos alimentos preparados na UAN, foi utilizada, como referência, a per capita diária da unidade (quantidade de carne crua, por pessoa, utilizada na preparação); e para os industrializados, tomou-se, como base, a indicação de porção da embalagem.

Ao final da refeição, o total de porções escolhidas foi dividido pelo número total de clientes avaliados, chegando-se à porção média de cada uma das opções. A quantidade de proteína dos pratos proteicos preparados na unidade foi calculada com o auxílio da tabela TACO (UNICAMP, 2013), e dos produtos industrializados, a partir do rótulo do produto. Os resultados foram comparados com os valores de referência da Organização Mundial da Saúde (WORLD..., 2003) e do Programa de Alimentação do Trabalhador (BRASIL, 2006), que preconiza que das 2000kcal, 600 a $800 \mathrm{kcal}$ provenham das grandes refeições e $10 \%$ a $15 \%$, desse valor calórico, sejam provenientes de proteína, ou seja - $80 \mathrm{kcal}$ a $120 \mathrm{kcal}$ em uma refeição. Foi considerado como aceitável o valor do limite para proteínas de $15 \%$ do VCT da refeição, o que corresponde a $30 \mathrm{~g}$ de proteína para os valores energéticos estabelecidos pelo PAT. 
Os dados, para a quantificação dos valores de sódio por porção, foram calculados a partir da quantidade de sal acrescentado nas preparações produzidas na unidade e convertida em sódio $(\mathrm{Na}), 1 \mathrm{~g}$ de sal $(\mathrm{NaCl})=400 \mathrm{mg}$ de sódio $(\mathrm{Na})$. Para as preparações industrializadas, foi utilizada a quantidade de sódio por porção descrita no rótulo da embalagem (Informação nutricional).

Os resultados obtidos foram comparados com os valores estabelecidos pelo Programa de Alimentação do Trabalhador (PAT), que preconiza que as grandes refeições (almoço, jantar e ceia) devam conter de 30 a 40\% de sódio do valor diário, ou seja, de 720 a 960mg de sódio. Para o estudo, foi utilizado, como referência, o valor máximo recomendado de sódio para uma refeição ( $40 \%$ do total diário ou 960 mg).

Este estudo foi realizado de forma observacional, sem contato com os usuários do restaurante, por interesse administrativo da própria unidade. Foram garantidos o sigilo em relação ao nome da empresa e a devolução dos resultados encontrados.

\section{RESULTADOS E DISCUSSÃO}

Durante 11 dias, foram observados, durante o almoço na UAN, em média, 164 comensais/dia. A Tabela 1 mostra as médias de cada um dos dois pratos proteicos servidos a cada dia, bem como a quantidade total média escolhida.

\begin{tabular}{llccc}
\multicolumn{5}{c}{ Tabela 1 - Média das escolhas proteicas em porções e em gramas e quantidade } \\
total. São Paulo, 2014.
\end{tabular}




\begin{tabular}{|c|c|c|c|c|}
\hline & Filé de frango grelhado & 0,77 & 100,10 & \multirow[b]{2}{*}{287,80} \\
\hline 6 & Frango assado - filé de coxa & 0,91 & 91,00 & \\
\hline & Bife à milanesa - contra filé & 1,23 & 196,80 & \\
\hline \multirow[t]{2}{*}{7} & $\begin{array}{l}\text { Filé de frango grelhado ao molho } \\
\text { de laranja }\end{array}$ & 1,27 & 152,40 & \multirow{2}{*}{435,20} \\
\hline & $\begin{array}{l}\text { Lasanha à bolonhesa coberta com } \\
\text { molho branco e queijo assada }\end{array}$ & 0,87 & 282,80 & \\
\hline \multirow[t]{2}{*}{8} & $\begin{array}{l}\text { Rolê de frango assado - filé de } \\
\text { coxa }\end{array}$ & 0,79 & 158,00 & \multirow{2}{*}{370,80} \\
\hline & $\begin{array}{l}\text { Hambúrguer de carne bovina } \\
\text { grelhado }\end{array}$ & 2,66 & 212,80 & \\
\hline \multirow[t]{2}{*}{9} & $\begin{array}{l}\text { Filé bovino diplomata grelhado - } \\
\text { contra filé }\end{array}$ & 1,29 & 167,70 & \multirow[t]{2}{*}{462,70} \\
\hline & $\begin{array}{l}\text { Escondidinho de carne seca } \\
\text { assado }\end{array}$ & 1,18 & 295,00 & \\
\hline \multirow[t]{2}{*}{10} & Lombo suíno assado & 0,55 & 55,00 & \multirow{2}{*}{185,00} \\
\hline & Linguiça toscana suína assada & 2,60 & 130,00 & \\
\hline \multirow[t]{4}{*}{11} & Espeto de carne assado & 0,65 & 78,00 & \multirow{2}{*}{146,00} \\
\hline & Peito peru assado & 0,68 & 68,00 & \\
\hline & Média das escolhas diárias & 2,56 & 147,77 & 295,54 \\
\hline & DP & 0,57 & 74,60 & 110,95 \\
\hline
\end{tabular}

Fonte: Elaborada pelos autores a partir dos dados da pesquisa. 2014.

A quantidade total de porções variou de 1,33 a 3,45 porções.

A Tabela 1 mostra uma gramagem de carne muito acima de qualquer recomendação. Embora o atual estudo faça referência apenas às escolhas, a livre demanda parece incentivar o consumo exagerado de pratos proteicos, corroborando o reportado na pesquisa de Hermans et al. (2012), em que o tamanho das porções influenciou no maior consumo. $O$ fato de restaurantes de empresas cobrarem o mesmo valor, independentemente da quantidade consumida, também parece influenciar na escolha, como já retratado por Vermeer et al. (2011; 2012). Rolls, Morris e Roe (2002) referem um aumento da obesidade relacionado ao aumento das porções. A denominação prato principal também parece contribuir para um maior consumo. Embora o nome se deva ao fato de ser o alimento que contribui com o maior custo para a 
unidade, pode gerar a falsa impressão de ser o mais importante e, portanto, o que deva ser mais consumido. Para tal, nesse tipo de restaurantes, deveria ser dissociado o termo "prato principal" de prato proteico. Segundo Abreu, Spinelli e Pinto (2016), em média as porções de pratos proteicos, em Unidades e Alimentação e Nutrição, variam conforme o alimento: carne sem osso - $160 \mathrm{~g}$; carnes com osso - $240 \mathrm{~g}$ e massas recheadas $200 \mathrm{~g}$.

Tabela 2 - Escolhas dos pratos proteicos preparados na UAN - média das porções. São Paulo, 2014.

\begin{tabular}{lc}
\hline \multicolumn{1}{c}{ Pratos Proteicos preparados na UAN } & Média (em porções) \\
\hline Maminha bovina assada & 1,23 \\
Bife de cupim bovino assado & 1,43 \\
Bife de contra filé grelhado ao molho Roty & 1,01 \\
Bife de carne de panela bovino & 1,81 \\
Estrogonofe de carne - miolo de alcatra & 1,65 \\
Filé de frango grelhado & 0,77 \\
Frango assado - filé de coxa & 0,91 \\
Bife à milanesa - contra filé & 1,23 \\
Filé de frango grelhado ao molho de laranja & 1,27 \\
Rolê de frango assado - filé de coxa & 0,79 \\
Filé bovino diplomata grelhado - contra filé & 1,29 \\
Lombo suíno assado & 0,55 \\
Espeto de carne assado & 0,65 \\
\hline Média das porções dos pratos proteicos preparados na UAN & 1,12 \\
\hline DP & 0,41 \\
\hline
\end{tabular}

Fonte: Elaborada pelos autores a partir dos dados da pesquisa. 2014.

Tabela 3 - Escolhas dos pratos proteicos processados - média das porções. São Paulo, 2014.

\begin{tabular}{lc}
\hline \multicolumn{1}{c}{ Pratos Proteicos Processados } & Média (em porções) \\
\hline Empanado de peito de frango com presunto e queijo frito & 1,17 \\
Pizza assada meio a meio calabresa e muçarela & 1,49 \\
Quibe frito & 1,99 \\
Torta de frango com palmito, milho e catupiry assada & 0,98 \\
Lasanha à bolonhesa coberta com molho branco e queijo & 0,87 \\
Hambúrguer de carne bovina grelhado & 2,66 \\
Escondidinho de carne seca assado & 1,18 \\
Linguiça toscana suína assada & 2,60 \\
Peito peru assado & 0,68 \\
\hline Média das porções dos pratos proteicos processados & 1,51 \\
\hline DP & 0,35 \\
\hline
\end{tabular}

Fonte: Elaborada pelos autores a partir dos dados da pesquisa. 2014. 
A alta ingestão de proteínas está relacionada ao aumento do risco de problemas renais, doenças crônicas e de osteoporose (VANIN et al., 2007; MORAIS; BURGOS, 2007; BRANDÃO; GIOVANONI, 2011) e, particularmente, o alto consumo de carnes (TABELAS 1,2 e 3) ao maior risco de câncer (GUERRA; MOURA; MENDONÇA, 2005) e de doenças cardíacas, possivelmente pelo fato de serem alimentos ricos em proteína animal e em gorduras saturadas (WHITNEY; ROLFES, 2008).

Ainda, sobre o consumo de carne, Bleil (1998) e os autores Ribeiro e Corção (2013) discorrem sobre o seu prestígio. Para esses, a carne carrega um enorme status - é símbolo de poder econômico, pois, para grande parte da população, que sempre viveu à margem do consumo, esse alimento ainda continua sendo o que mais demonstra a condição econômica.

Figura 1 - Quantidade diária de proteína fornecida pelos pratos proteicos da UAN, comparada com a recomendação do PAT. São Paulo, 2014.

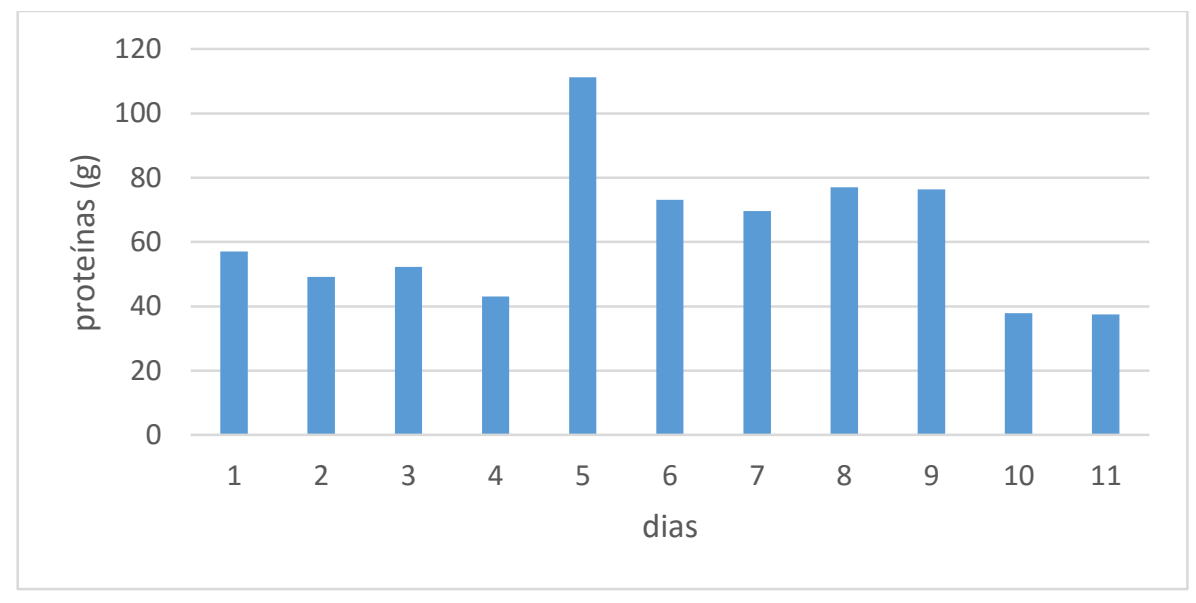

Fonte: Elaborada pelos autores a partir dos dados da pesquisa. 2014.

Observa-se, na Figura 1, um valor médio de proteína de 62, 2 g proveniente do prato proteico, equivalente ao dobro da quantidade máxima recomendada pelo PAT para a refeição almoço $(30 \mathrm{~g})$ apenas nesse tipo de preparação, corroborando o trabalho de Carneiro, Moura e Souza (2013), que, também, identificou nutrientes proteicos, numa refeição almoço, inadequados em comparação aos parâmetros do PAT. Esse resultado é uma limitação do trabalho, pois não foi estabelecida a adequação em relação ao VCT da refeição, em números absolutos mostram um excesso de proteínas por refeição. 
Tabela 4 - Quantidade de sódio ( $\mathrm{Na}$ ) em miligramas $(\mathrm{mg})$ por tipo de preparação e em porcentagem sobre o total de pratos proteicos servidos na UAN, considerando a referência de $960 \mathrm{mg}$ de Na para a refeição almoço. São Paulo, 2014.

\begin{tabular}{crrrr}
\hline Dias & $\begin{array}{r}\text { Prato Proteico 1 } \\
(\mathrm{mg})\end{array}$ & $\begin{array}{r}\text { Prato Proteico 2 } \\
(\mathrm{mg})\end{array}$ & \multicolumn{1}{c}{$\begin{array}{c}\text { Total } \\
(\mathrm{mg})\end{array}$} & \multicolumn{1}{c}{$\begin{array}{c}\text { Total } \\
(\%)\end{array}$} \\
\hline 1 & 262,40 & 1399,32 & 1661,72 & 173,09 \\
2 & 352,00 & 716,69 & 1068,69 & 154,88 \\
3 & 372,92 & 618,89 & 991,81 & 143,74 \\
4 & 346,43 & 423,36 & 769,79 & 80,81 \\
5 & 879,69 & 404,40 & 1284,09 & 186,10 \\
6 & 312,00 & 656,00 & 968,00 & 140,29 \\
7 & 609,60 & 1017,03 & 1626,63 & 169,44 \\
8 & 632,00 & 1556,10 & 2188,10 & 227,91 \\
9 & 536,64 & 1159,94 & 1696,58 & 176,73 \\
10 & 195,55 & 1170,00 & 1365,55 & 142,19 \\
11 & 208,00 & 595,68 & 803,68 & 83,71 \\
\hline Média de Na & 427,93 & 883,40 & 1311,33 & 136,60 \\
\hline DP & 211,94 & 396,04 & 444,16 & - \\
\hline
\end{tabular}

Fonte: Elaborada pelos autores a partir dos dados da pesquisa. 2014.

A média de $\mathrm{Na}$ dos alimentos processados foi de $917,92 \mathrm{mg}$ e dos alimentos proteicos preparados na UAN - 465,48 mg.

Embora a média de porções da escolha proteica (Tabela 1) tenha sido na ordem de $35 \%$ superior para os alimentos industrializados processados $(1,51 \times 1,12)$, é possível observar que a diferença dos valores de sódio, para esses alimentos, foi de, praticamente, $100 \%$. Poucos estudos têm sido feitos relacionando as proteínas, numa única refeição, aos valores de sódio nela contidos. Geraldo, Bandoni e Jaime (2008) e Vanin et al. (2007) realizaram pesquisa sobre aspectos dietéticos de empresas participantes do PAT na cidade de São Paulo. Nesses estudos as proteínas representaram, $18,9 \%$ e $20,6 \%$ do valor calórico das refeições, respectivamente. Essas pesquisas chamam, ainda, a atenção para os valores elevados de gorduras e colesterol, porém pouca atenção é dada à porção de sódio relacionada à ingestão proteica.

Uma limitação do estudo é o escasso número de publicações sobre o tema, restringindo a possibilidade de comparação. Estudos, como os de Salas et al. (2009) e Barbosa, Barros e Spinelli (2012), encontraram valores de sódio maiores, pois consideraram todos os alimentos consumidos na refeição e não somente o prato proteico servido no almoço. Koehnlein e Carvajal (2009) relatam uma quantidade total de sódio maior para a refeição com frango do que para a de carne como prato proteico. 
Embora o sódio seja vital para diversas atividades celulares, a sua ingestão excessiva pode levar a problemas, como a elevação da pressão arterial (2010), a osteoporose (2009), o câncer gástrico (1997), a síndrome metabólica (2005), entre outros.

O valor de sódio (TABELA 4), dos dias observados, é menor que os encontrados no estudo de Spinelli et al. (2011), em 15 restaurantes comerciais de Mogi das Cruzes, determinados por análise laboratorial, possivelmente mostrando que os cálculos com o uso de tabelas e de rótulos podem indicar valores menos precisos.

Assim, na presente pesquisa, em 4 dos 11 dias estudados, foi verificado que os comensais se serviram somente com o prato proteico da refeição almoço, acima de $60 \%$ das recomendações diárias de sódio, para todas as refeições do dia.

O valor de sódio encontrado nas médias das porções proteicas servidas na UAN foi substancialmente expressivo, especialmente porque se verificou que as duas escolhas proteicas servidas no almoço continham elevadas quantidades de sódio, sem considerar a quantidade de sódio do restante do cardápio do almoço. Esse achado é bastante relevante, pois existe uma correlação entre o consumo excessivo de sódio e o desenvolvimento de hipertensão arterial, que já alcança $24,3 \%$ da população brasileira, segundo dados da Vigitel (2012).

Dessa maneira, este estudo aponta para a necessidade de implantação de medidas para redução do consumo excessivo de sódio. Entre estas, primeiramente, a redução de preparações industrializadas. Em segundo lugar, o desenvolvimento de um programa de treinamento, para os colaboradores, sobre a utilização de temperos naturais, como orégano, cheiro verde, alho, cebola, limão, manjericão, mostarda, colorau e ervas de um modo geral; redução ou exclusão do uso de caldos de carne, galinha e bacon. Em terceiro lugar, limitar, progressivamente, e controlar o sal nas preparações de alimentos na UAN (BRASIL, 2012a; SPINELLI et al., 2011).

Para Bleil (1998), o hábito de consumir produtos cada vez mais industrializados é uma marca da modernidade e uma tendência mundial, fazendo parte do fenômeno da globalização. Porém percebe-se que os produtos industrializados têm, no Brasil, uma facilidade maior para conquistarem espaço. A cultura da quantidade e não do sabor, a ausência de uma tradição ligada à gastronomia, que aqui é vista como um luxo e não uma arte, como a música ou a pintura, favorecem a introdução de novos produtos que têm status, principalmente junto aos mais jovens.

Com relação aos alimentos processados, uma das iniciativas do Ministério da Saúde ocorreu em 2010, com o I Seminário de Redução de Sódio desses alimentos, e que teve o objetivo de debater a situação e o posicionamento de diferentes setores sociais visando à redução do consumo de sódio em todo país. 
Os debates comprovaram a necessidade de constituição de estratégias de ações. Umas das questões mais relevantes das discussões foi que a educação nutricional e alimentar por si só não é efetiva, sendo necessário que haja regulamentação de alimentos, em relação à redução de sódio nos alimentos processados.

Para tal, o Ministério da Saúde elaborou o Plano de Redução do Sódio em Alimentos Processados, que é componente do Plano de Redução do Consumo de Sal pela População Brasileira (BRASIL, 2012a; BRASIL, 2012b). Esse prevê a redução do consumo para $5 \mathrm{~g}$ de sal, per capita, por dia (2.000 mg de sódio) até 2.020 , atingido por redução voluntária do teor de sódio nos alimentos processados (SALAS et al., 2009).

\section{CONCLUSÃO}

A livre demanda de pratos proteicos, de um modo geral, proporciona uma refeição hiperproteica com um porcionamento inadequado, em relação às quantidades previamente estimadas.

Caso essas preparações proteicas não apresentem controle do uso de amaciantes, molhos e/ou condimentos e sal, ou se tratem de alimentos processados industrialmente, podem apresentar, ainda, altas quantidades de sódio, tornando-se um fator de risco para doenças crônicas não transmissíveis.

É necessário que se implantem programas nutricionais educativos para os usuários da UAN, voltados para a conscientização da redução do consumo de proteínas, visto que, com sistema self service, não há outra forma de controle de consumo.

As evidências que ligam o maior consumo de sódio com as enfermidades crônicas são, notoriamente, sólidas para a justificativa da necessidade da redução do teor de sal nas preparações proteicas e na diminuição da oferta de pratos proteicos processados.

São necessários estudos similares com maior número de estabelecimentos, pois ainda existem poucas publicações científicas sobre a oferta de proteína e de sódio em restaurantes institucionais, limitando a possibilidade de ações que visem à melhora da qualidade de vida do trabalhador.

\section{REFERÊNCIAS}

ABREU, E.S.; SPINELLI, M.G.N.; PINTO, A.M.S. Gestão de unidades de alimentação e nutrição: um modo de fazer. 5. ed. São Paulo: Metha; 2016.

BARBOSA, M. R. A. S.; BARROS, V. A. M. M.; SPINELLI, M. G. N. Teores de Sódio em Refeições Servidas em Unidade de Alimentação e Nutrição na Cidade de São Paulo-SP, Nutrição em Pauta, 2012. Disponível em: <http://www.nutricaoempauta.com.br/lista_artigo.php?cod=2096>. Acesso em: 10 abr. 2018. 
BLEIL, S. I. O Padrão Alimentar Ocidental: considerações sobre a mudança de hábitos no Brasil. Cadernos de Debate, v. 1, p. 6-25,1998.

BRANDÃO, A. R.; GIOVANONI, A. C. Comparação dos cardápios oferecidos em uma Unidade de Alimentação e Nutrição do município de Teutônia com o Programa de Alimentação do Trabalhador. Revista Destaques Acadêmicos, v. 3, n. 3, p. 89-94. 2011.

BRITO, A.; SPINELLI, M. G. N. Oferta de sódio oriundo de alimentos industrializados em restaurantes institucionais. DEMETRA: Alimentação, Nutrição \& Saúde, v. 11, p. 321-336, 2016.

BRASIL. Programa de Alimentação do Trabalhador - PAT - Portaria interministerial no 66, de 25 de agosto de 2006. Diário Oficial da União, Brasília, 2006.

BRASIL. Plano de Redução do Sódio em Alimentos Processados. 2012.

Disponível em: <http://www.abia.org.br/anexos /

CriteriosparamonitoramentoeavaliacaodoPlano27jan.pdf>. Acesso em: 1 abr. 2014.

BRASIL. PORTAL DA SAÚDE, 2012b. Disponível em:

<http://portalsaude.saude.gov.br/ index.php/o-ministerio/aisa/noticias-aisa/14342-vejaa-integra-da-fala-do-ministro-chioro-em-almoco-da-abia>. Acesso em: 5 maio 2014.

CARNEIRO, N. S.; MOURA, C. M. A.; SOUZA, S. C. C. Avaliação do almoço de uma UAN segundo o PAT. Alim. Nutr. Braz. J. Food Nutr., v. 24, n. 3, p. 361-365, 2013.

CARVALHO, A. M. et al. Excessive meat consumption in Brazil: diet quality and environmental impacts. Public Health Nutrition, v. 16, n. 10, p. 1893-1899, 2013.

GERALDO, A. P. G.; BANDONI, D. H.; JAIME, P. C. Aspectos dietéticos das refeições oferecidas por empresas participantes do Programa de Alimentação do Trabalhador na Cidade de São Paulo, Brasil. Rev. Panam. Salud Publica, v. 23, n. 1, p. 9-25, 2008.

GUERRA, M. R.; MOURA, G. C. V.; MENDONÇA, G. A. S. M. Risco de câncer no Brasil: tendências e estudos epidemiológicos mais recentes. Revista Brasileira de Cancerologia. v. 51, n. 3, p. 227-234, 2005.

HERMANS, R.C. et al. How much should I eat? Situational norms affect young women's food intake. Br J Nutr., v. 107, n. 4, p. 588-594, 2012.

IBGE. Instituto Brasileiro de Geografia e Estatística. Pesquisa de Orçamentos Familiares 2008-2009. Rio de Janeiro, 2011. Disponível em:

<http://www.ibge.gov.br/home/estatistica/populacao/condicaodevida /pof/2008_2009_analise_consumo/pofanalise_2008_2009.pdf>. Acesso em: 23 jun. 2014.

KOEHNLEIN, E. A.; CARVAJAL, A.L.S.S. Avaliação do teor de sódio adicional do almoço servido em uma unidade de alimentação e nutrição de Maringá-PR.V EPCC. Encontro Internacional de Produção Científica. Maringa, 2009.

MORAIS, G. Q.; BURGOS, M. G. P. A. Impacto dos nutrientes na saúde óssea: novas tendências. Revista Brasileira de Ortopedia, v. 42, n. 7, p. 189-94, 2007. 
RIBEIRO, C.S.G; CORÇÃO, M. O consumo de carne no Brasil: entre valores socioculturais e nutricionais. Demetra, v. 8, n. 3, p. 425-438, 2013.

ROLLS, B. J.; MORRIS, E. L.; ROE, L. S. Portion size of food affects energy intake in normal-weight and overweight men and women. Am J Clin Nutr., v. 76, n. 6, p. 120713, 2002.

SALAS, C. K. T. et al. Teores de sódio e lipídios em refeições almoço consumidas por trabalhadores de uma empresa do município de Suzano, SP. Rev. Nutr., v. 2, n. 3, p. 331-339, 2009.

SAVIO, K. E. O. et al. Avaliação do Almoço Servido a Participantes do Programa de Alimentação do Trabalhador. Rev Saúde Públ., v. 39 n. 2, p. 145-155. 2005.

SPINELLI, M.G.N.; KAWASHIMA, L.M.; EGASHIRA, E.M. Análise de sódio em preparações habitualmente consumidas em restaurantes self service. Alim. Nutr., v. 22, n.1, p. 55-61, 2011.

UNICAMP. Tabela Brasileira de Composição de Alimentos. Campinas:

Universidade Estadual de Campinas. Disponível em:

<http://www.unicamp.br/nepa/taco/>. Acesso em: nov. 2013.

VANIN, M. et al. Adequação nutricional do almoço de uma unidade de alimentação e nutrição de Guarapuava - PR. Revista Salus-Guarapuava., v.1, n.1, p. 31-38, 2007.

VERMEER, W. M. et al. The process evaluation of two interventions aimed at portion size in worksite cafeterias. J Hum Nutr Diet., v. 25, n. 2, p. 180-188, 2012.

VERMEER, W. M. et al. Small portion sizes in worksite cafeterias: do they help consumers to reduce their food intake? Int J Obes., v. 35, n. 9, p. 1200-1207, 2011.

VIGITEL. Disponível em: <http://www.sbpt.org.br/downloads/arquivos/vigitel_ 2012.pdf $>$. Acesso em: 02 maio 2014.

WHITNEY, E.; ROLFES, S.R. Nutrição. v 1. Brasil: Cencage Learning, 2008.

WHITWORTH, J. A. Statement on management of hypertension. J Hypertesis. v. 21, n. 11, p. 1983-1992,2003.

WORLD HEALTH ORGANIZATION. Statement on management of hypertension. $\mathbf{J}$ Hypertesis. v. 21, n.11, p. 1983-1992, 2003. 